\title{
PATHOLOGY OF HUMAN SCHISTOSOMIASIS
}

\author{
ZILTON A. ANDRADE \\ Centro de Pesquisas Gonçalo Moniz - FIOCRUZ, Rua Valdemar Falcão, 121, 41945 Salvador, BA, Brasil
}

A pathologist working in an endemic area of schistosomiasis frequently sees lesions determined by the presence of schistosome eggs in various tissues, especially in the liver and intestines. These are granulomas which vary considerably in size, number as well as in types and amount of inflammatory cells, necrosis and fibrosis. Most of the times these periovular granulomas are incidental findings with no relationship to the clinical history of the patients and they reflect the presence of cases of mild (frequently asymptomatic) schistosomiasis that comprise $95 \%$ of the chronically infected population. The other 5\% are represented by cases of severe or advanced schistosomiasis characterized by clay pipe stem fibrosis of the liver and which can be complicated by cardio-pulmonary. renal, splenic and other changes. These severe forms of schistosomiasis concern the pathologist particularly and therefore will be especially considered in the present article.

\section{CLASSIFICATION}

Morphological features and a few pertinent comments on the pathology of Manson' schistosomiasis in human will be presented according to the following classification:

Acute schistosomiasis

Chronic schistosomiasis

A - Mild schistosomiasis

a) Symptomatic

b) Asymptomatic.

B - Severe or advanced schistosomiasis

a) Hepatic form

b) Hepatosplenic form

i) with cor pulmonale

ii) with glomerulopathy

iii) with splenic lymphomas

iv) with prolonged infections septicemic salmonellosis viral hepatitis B.

Special forms of schistosomiasis

A - Ectopic schistosomiasis

B -- Pscudo-neoplastic schistosomiasis
Acute schistosomiasis - In the few cases of acute schistosomiasis in human in which pathologic examination has been performed (Diaz-Rivera et al., 1956; Bogliolo \& Neves, $1965)$, the severity of the inflammatory reaction around mature eggs in tissues has been emphasized. The periovular granulomas are large, with predominant necroticexudative features and appear as translucid granules disscminated on the serosal surface of liver and intestines. Microscopically, they disclose central necrosis and dense eosinophilic infiltration as predominant characteristics. In the liver and spleen there are also non specific reactive changes, with many eosinophils and macrophages, and these rather diffuse changes have led some to consider acute schistosomiasis as related to serum sickness, or to inmediatehypersensitivity disease (Hiatt et al., 1979).

Rarely, focal inflammatory changes around disintegrating larvae (schistosomula) have been described (Diaz-Rivera et al., 1956; Bogliolo \& Neves, 1965), a finding that is probably related to a primary massive infection.

Pathogenesis of this form of schistosomiasis is obscure, but it is often admitted that hypersensitivity to schistosomal antigens plays a major role. Since acute schistosomiasis is not usually seen in people living in endemic areas, but in visitors, it is assumed that desensitization of indigenous populations may be processed early in life, or even congenitally.

Chronic mild schistosomiasis - This is the usual form of schistosomiasis observed in endemic regions. During early infection, probably when immunological modulation of the egg-induced lesions are not yet completed, there may be manifestations of abdominal pain and diarrhea. However, most of the times, the subjects living in endemic areas and who are passing eggs in the stools are asymptomatic. and the non specific general complaints which can be obtained from some of them do not differ from those presented by non-infected people living under the same socio-economic conditions. 
Pathology is represented by isolated periovular granulomas, especially seen in the liver. These granulomas are predominantly fibrotic and almost always contain variable number of macrophages and eosinophils.

Chronic severe schistosomiasis - The main lesion in such cases is clay-pipe stem fibrosis of the liver as described by Symmers (1904). It is related to high parasite burden, with the production of numerous eggs that, as observed experimentally (Andrade, 1987), at first cause obstruction of the finest portal radicles at the periphery of the portal system. From then follow: increased intrahepatic portal pressure; the opening-up of fine collaterals around the main portal branches; the subsequent lodgment of many eggs within these periportal vessels. With the resulting granuloma formation and increased deposition of interstitial matrix and collagen (Fig. 1) periportal fibrosis and vascular destruction ensue. The final result is the production of a stellate portal fibrosis all along the branching of the portal vein system, while the liver parenchyma mantains its normal looking ap. pearance, which concurs to give to the cut surface of the liver a very characteristic gross appearance (Fig. 2). Within the fibrosed and enlarged portal space there are partial or total obstructive vascular lesions (intravascular periovular granulomas, thrombosis with organization and re-canalization, phlebosclerosis, sclcrosing and retraction. intimal fibrous thickening) while many thin-walled vessels show telangiectasia (angiomatoid change) and congestion.

As a consequence of intrahepatic venous obstruction there occurs a progressive hypertrophy of the hepatic artery (Andrade \& Cheever, 1971). Hepatic parenchyma then becomes too dependent from arterial blood and usually undergoes focal ischemic necrosis when the arterial perfusion decreases, such as happens during massive gastric bleeding from ruptured esophageal varices. In cases of non-fatal bleeding the focal areas of necrosis are transformed into areas of post necrotic scarring, with formation of fibrous septa and nodular parenchymal regeneration. When such arcas are seen in material from surgical biopsics, a mistaken diagnosis of cirrhosis can be made, but a true cirrhosis is not usually seen in advanced pipestem schistosomiasis (Andrade, 1968).

Increased arterial blood flow into the sinusoids is also responsible for sinusoidal hypertension as measured by the wedged portal vein catetherization plus temporary clamping of hepatic artery (Alves et al., 1977). Probably the increased sinusoidal pressure may induce capillarization of the sinusoidal walls, which interferes with adequate hepatocellular function.

A pure hepatic form of pipe-stem fibrosis can sometimes be observed. Portal hypertension fails to develop in such cases apparently in consequence of good compensation by the collateral circulation or by some intra-hepatic vascular adjustment. Esophageal varices do not form and there is no splenomegaly and thus the diagnosis of the hepatic lesion is made at autopsy or during surgery (Prata \& Andrade, 1963). The real prevalence of hepatic pipe stem fibrosis without splenomegaly (hepatic form of advanced schistosomiasis) is not known.

Schistosomal cor pulmonale - This is a severe complication of advanced hepatic schistosomiasis that results from the diverting of many schistosome eggs from the portal to the pulmonary vessels, via collateral circulation.

In the lungs the eggs are located first in arterial pre-capillaries and, when sufficiently numerous to cause vascular peripheral obstruction, there results increased intra-pulmonary artery hypertension, which provokes the opening up of fine collaterals comming off at right angles from large, medium and small branches of the pulmonary artery. where the newly arriving eggs are subsequently lodged (Sadigursky \& Andrade, 1982). The involvement of large and medium-sized segments of the pulmonary artery by the periovular granulomas, is an indication of the presence of cor pulmonale regardless its degree or intensity.

The fresh arterial and arteriolar lesions are dominated by endothelial cell proliferation with differentiation of new vascular lumina. Fibrin deposits are scanty and overt vascular thrombosis is exceptional. Later changes are represented by collagen deposition and formation of new vascular canals, both inside and outside the primitive arterial lumen, giving rise to the so-called "angiomatoid" lesion (Fig. 3).

This latter is not a venous-arterial communication as some believed, but an exclusive arterial lesion, as can be observed in plastic casts obtained with the injection-corrosion technique (Sadigursky \& Andrade, 1982). 


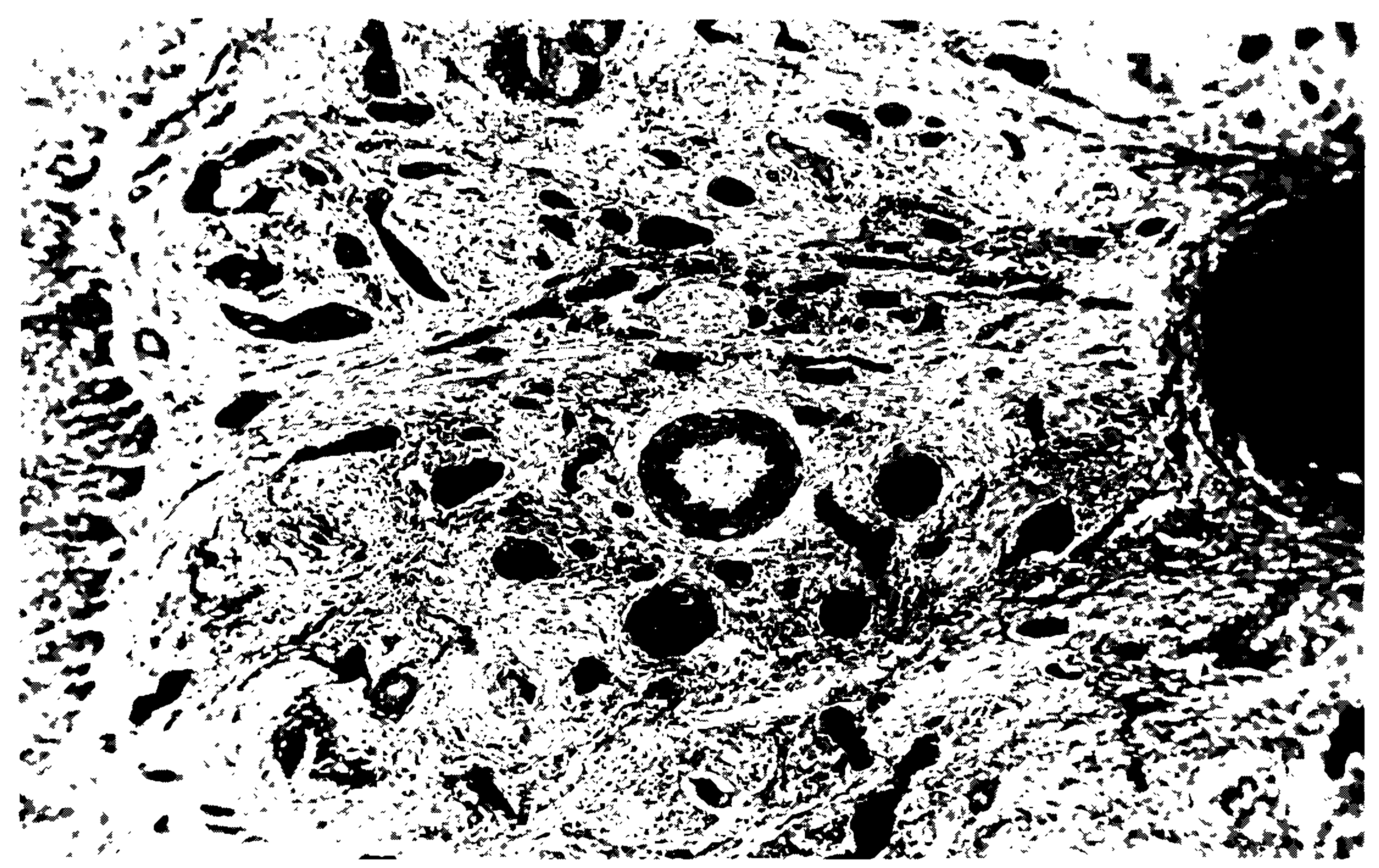

Fig. 1: microscopic appearance of clay-pipe stem fibrosis of the liver. Due to the presence of congestion, telangiectasia is prominent and gives an angiomatoide appearance to the fibrosed portal space. There can also be seen some periovular granulomas and diffuse infiltration by mononuclear inflammatory cells. Hematoxylin and Eosin, X 100.

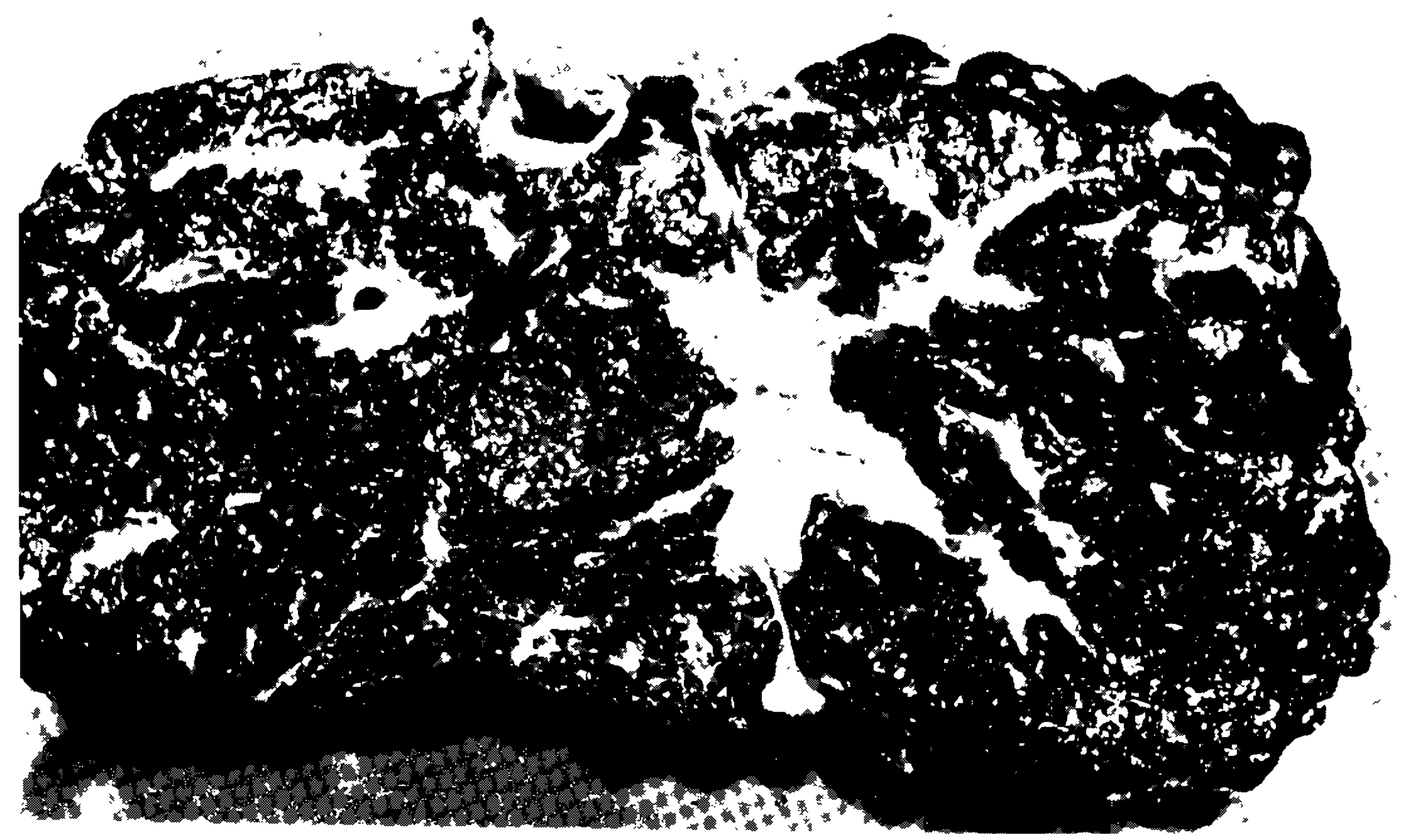

Fig. 2: characteristic gross features of clay-pipe stem fibrosis of schistosomiasis: fibrosed and enlarged portal spaces against a background of normal looking parenchyma. Although the external surface is nodular, there is no nodular transformation of the parenchyma and therefore no associated cirrhosis. 


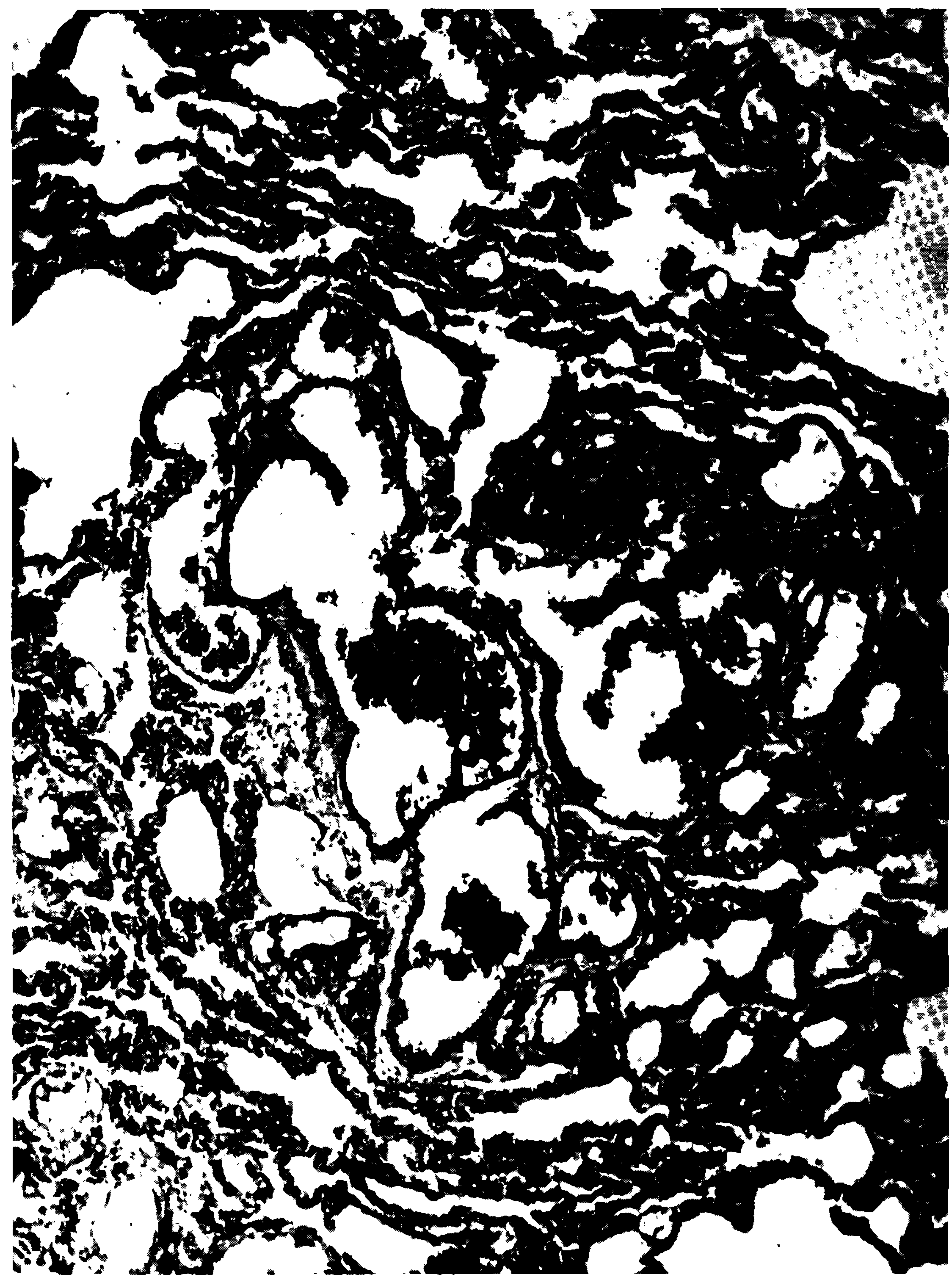

Fig. 3: section of a pulmonary artery showing a plexiform lesion from a case of schistosomal cor pulmonale. There is a labyrinth formed by numerous vascular lumina, both inside and outside the walls of the primitive artery. Hematoxylin and Eosin. X 150. 
Pathogenesis of pulmonary vascular lesions is in many ways similar to that causing pipe stem fibrosis of the liver.

The lesions are similarly obstructive and severely distort the normal straight vascular branching. A main difference is that the hepatic vascular changes can undergo a surprising degree of repair and remodelling following curative treatment of schistosomiasis, while the pulmonary arterial changes are unaffected by such treatment. That has been observed both in man (Emanuel et al., 1986) and experimentally (Almeida \& Andrade, 1983). Cyanosis is not a component of the clinical picture of schistosomal cor pulmonale. However, rather rarely, patients with hepatosplenic schistosomiasis may exhibit cyanosis in the absence of pulmonary hypertension. It has been suggested that, such as demonstrated for hepatic cirrhosis, porto-pulmonary collaterals can also develop in hepato-splenic schistosomiasis, thus diverting unsaturated blood to the systemic circulation, enough to provoke a cyanotic syndrome.

Schistosomal glomerulopathy - The suggestion that chronic renal disease could be a complication of hepato-splenic schistosomiasis came after clinical observations that nephrotic syndrome was frequently present in such patients, plus necropsy data revealing that $15 \%$ of the hepato-splenic subjects had associated chronic glomerulonephritis, mostly of the mesangio-capillary type, and that over $50 \%$ of the remaining presented focal glomerular sclerosis or increased mesangial cellularity with mesangial matrix expansion (Andrade \& Van Marck, 1985).

Several types of renal changes, including glomerulonephritis, can be observed in monkeys, rabbits, hamsters and mice with heavy and prolonged infection with either $S$. mansoni and $S$. japonicum. Pathogenesis of the glomerulonephritis seems to be mediated by immunocomplexes since schistosomal antigens and several classes of immunoglobulins and complement have been detected in the glomeruli of patients and experimental animals with schistosomiasis.

An antigen present in the intestinal epithelium of adult worms and known to be a polyssacharide of hight molecular weight (1.000 Daltons) has been particularly suspected of being a major factor in causing glomerular changes.
Its presence has been detected in the circulating blood and in urine form animals with heavy Schistosoma mansoni infection, but not in animals with light infection. In such cases, the presence of the antigen can be disclosed within phagocytic cells of the hepatic sinusoids. This explains why schistosomal glomerulopathy is restricted to patients with the hepato-splenic form of the disease, since collateral circulation can permit the antigen to by-pass the hepatic filter barrier and get to the general circulation.

Searching for proteinuria in people living in an endemic area of schistosomiasis, Bina et al. (1985) were able to demonstrated that individuals with hepato-splenic schistosomiasis were more prone to present proteinuria than similar paired controls with mild schistosome infections. Proteinuria was detected in $24.7 \%$ of 89 hepato-splenic cases, and in $4.6 \%$ of 86 socalled hepato-intestinal cases. Considering only significative proteinuria (over $30 \mathrm{mg} / 100 \mathrm{ml}$ ) it was present in 8 hepato-splenics and in only one from the other group.

Splenic lymphomas - Non-Hodgkin, nodular lymphomas of different cellular composition, can be seen to arise primarily in $1 \%$ of the big spleens of hepato-splenic schistosomiasis. A similar situation is known to occur in patients with the big spleen syndrome seen in areas of endemic malaria. The Brazilian cases occurred predominantly in aged women (Andrade \& Abreu, 1971; Paes \& Marigo, 1981), probably the only type of lymphoma to predominante in females. The only histological peculiarity was that the canter of the neoplastic nodules often contained an amorphous, amyloid-like material, rich in immunoglobulin, besides the fact that the lymphoma was seated on a spleen already showing the classical alterations of congestive splenomegaly.

Prolonged infections - At least two types of infections are known to present a prolonged clinical course in patients with hepato-splenic schistosomiasis: septicemic salmonelosis and B-viral hepatitis.

Pathologic investigations are practically nonexistent for prolonged salmonelosis. In materials from liver biopsies one can see focal parenchymal necrosis and considerable degree of hypertrophy of Kupffer cells, and variable degree of mononuclear cell infiltration with predominance of plasma cells in the portal spaces, changes 
that can be generally described as "non-specific reactive hepatitis". Pathogenesis is obscure. It has been shown that the bacteriae can be intimately attached to the adult worm tegument or can also be found inside the worm body, apparently protected from the host immune response. A defficient clearance of injected salmonelae has been demonstrated in the spleen of mice infected with $S$. mansoni.

Hepatitis B infection is 7 times more frequent in patients with hepato-splenic schistosomiasis than in candidates for blood donnors in Salvador, Bahia - Brazil (Lyra et al., 1976). This infection tends to run a chronic course, with prolonged viraemia. Usually the infected patients develop chronic active hepatitis, a condition that may cause decompensation of hepato-splenic disease, when signs of hepatocellular failure are added to the preexistent syndrome of portal hypertension.

The higher prevalente of $\mathrm{B}$-hepatitis virus infection in hepato-splenic patients can be explained because they present a chronic condition, are frequently hospitalized, frequently medicated by parenteral route, receive blood transfusions for gastric bleedings or during surgery, and so on. However, the reason why they develop prolonged infection with active hepatitis has not been investigated.

Ectopic schistosomiasis - When periovular granulomas form outside portal and pulmonary circulation, it is considered as ectopic schistosomiasis. Most of the time it represents a curiosity for the pathologist examining surgical or autopsy materials. Periovular granulomas can be found in such strange sites as in the skin of the nose, in other areas of the skin, in thyroid, kidneys, pancreas, testicles, ovary, uterus, adrenals, lymph nodes, heart, prostate, brain and spinal cord (Andrade \& Bina, 1983). Usually the eggs reach the tissues by arterial or venous embolization, and in such cases they are few, scattered, and do not give origin to clinical symptoms. However, when ectopic deposition results from migration and oviposition by paired worms, such as may occur in the spinal cord, a greater number of eggs can be deposited in a limited area of tissue giving rise to chronic inflammatory changes and fibrosis, which may have considerable clinical implications.

Ectopic Manson's schistosomiasis is an important form only in those rare cases in which the spinal cord is involved. Vasical and anal sphincteric disturbances are then the rule. Radicular pain, paraplegia, neurogenic bladder can also result from the schistosomal lesions in the distal portions of the spinal cord.

Pseudo-neoplastic schistosomiasis - This form of schistosomiasis appears when there is a concentrated deposition of eggs and a considerable fibroplastic response on the part of the host. This combination of factors gives origin to a fibrotic tumoral mass that can be easily confused with a neoplasm, usually a malignant one. Similar to the severe cases of spinal cord involvement, pseudo-neoplastic schistosomiasis can also occur in patients with only mild schistosome infections. Tumor masses may be found in the intestines, mesentery, in peri-rectal or peri-colonic areas, may be presented as intestinal polyps, or may simulate lymphoma by involving the mesenteric lymph nodes (Abrantes \& Katz, 1964). In the intestines, the fibrotic reaction is outstanding in the mucosa, submucosa and subserosa. The sigmoid region is the portion involved and the excessive fibrous tissue may cause stenosis and may simulate an adenocarcinoma of the colon both grossly and radiologically. Schistosomal polyps are rare and are usually seen in children. In Egypt they are frequent in adults, and give rise to a syndrome of anemia, protein-loosing enteropathy and bloody diarrhea.

The frequency with which the pathologic manifestations here considered were seen in 223 consecutive necropsies performed in cases of hepatosplenic schistosomiasis appeared in a past issue of Memórias. (Andrade \& Bina, 1983), which should be consulted by those interested.

\section{REFERENCES}

ABRANTES, W. L. \& KATZ, K., 1964. Formaçāo conjuntivo-hiperplásica (pseudo tumoral) de esquistossomose mansoni com localização intestinal. An. XIII Jornada Bras. Puer. Pediat., p. 358-368, Porto Alegre.

ALMEIDA, M. A. C. \& ANDRADE, Z. A., 1983. Effect of chemotherapy on experimental pulmonary schistosomiasis. Am. J. Trop. Med. Hyg., 32: 1049-1054.

ALVES, C. A. P.; ALVES, A. R.; ABREU, W. N. \& ANDRADE, Z. A., 1977. Hepatic artery hypertrophy and sinusoidal hypertension in advanced schistosomiasis. Gastroenterology, 72: 126-128.

ANDRADE, Z. A., 1968. Can schistosomiasis cause hepatic cirrhosis? Gaz. Med. Bahia, 68: 34-41. 
ANDRADE, Z. A., 1987. Pathogenesis of pipe stem fibrosis of the liver. (An experimental trial). Mem. Inst. Oswaldo Cruz, 82: 325-334.

ANDRADE, Z. A. \& ABREU, W. N., 1971. Follicular lymphomas of the spleen in patients with hepatosplenic schistosomiasis mansoni. Am. J. Trop. Med. Hyg., 20: 237-243.

ANDRADE, Z. A. \& BINA, J. C., 1983. A patologia da forma hepato-esplênica da esquistossomose mansoni em sua forma avançada. Mem. Inst. Oswaldo Cruz, 78: 285-305.

ANDRADE, Z. A. \& CHEEVER, A. W., 1971. Alterations of the intrahepatic vasculature in hepatosplenic schistosomiasis mansoni. Am. J. Trop. Med. Hyg., 20: 425-432.

ANDRADE, Z. A. \& VAN MARCK, E., 1784. Schistosom:1 glomerular disease. (A review). Mem. Inst. Oswaldo Cruz, 79: 499-506.

BINA, J. C.; ANDRADE, Z. A.; DIETZE, R. \& PRATA, A., 1985. A field study of proteinuria in individuals infected with Schistosoma mansoni. Rev. Soc. Bras. Med. Trop., I8: 7-10.

BOGLIOLO, L. \& NEVES, J., 1965. Ocorrência da hepatite na forma aguda ou toxêmica da esquistossomose mansoni, antes da maturação dos vermes e da postura dos ovos, com algumas considerações sobre a forma aguda ou toxêmica da esquistossomose. An. Fac. Med. Univer. Minas Gerais, 2:
47-74.

DIAZ-RIVERA， R. S.; RAMOS-MORALES， F.; KOPPISCH, E.; GARCIA-PALMIERI, M. R.; CINTRON-RIVERA, A. A.; MARCHAND, E. J.; GONZALES, O. \& TORREGROSSA, M. V., 1956. Acute Manson'schistosomiasis. Am. J. Med., 21: 918-943.

EMANUEL, A.; PRATA, A.; BINA, J. C. \& GUIMARĀES, A., 1986. Hipertensão pulmonar esquistossomótica persistente em paciente após reversão da forma hepatoesplênica: Apresentação de um caso. Rev. Soc. Bras. Med. Trop., 19:171-172.

HIATT, R. A.; SOTOMAYOR, R.; SANCHEZ, G.; ZAMBRANA, M. \& KNIGHT, W. B., 1979. Factors in the pathogenesis of acute schistosomiasis mansoni. J. Infec. Dis., 139: 659-666.

PAES, R. A. P. \& MARIGO, C., 1981. Linfoma folicular gigante e esquistossomose mansônica. Rev. Inst. Med. trop. Sâo Paulo, 23: 287-292.

PRATA, A. \& ANDRADE, Z. A., 1963. Fibrose hepática de Symmers sem esplenomegalia. O Hospital, (Rio de Janeiro), 63: 617-623.

SADIGURSKY, M. \& ANDRADE, Z. A., 1982. Pulmonary changes in schistosomal cor pulmonale. Am. J. Trop. Med. Hyg., 31: 779-784.

SYMMERS, W. St. C., 1904. Note on a new form of liver cirrhosis due to the presence of the ova of Bilharzia haematobia. J. Pact. Bact., 9: 237-239. 